\title{
Expression patterns of hepatic genes involved in lipid metabolism in cows with subclinical or clinical ketosis
}

\author{
Yiwei Zhu, ${ }^{*}$ Guowen Liu, ${ }^{*}$ Xiliang Du, Zhen Shi, Meiyu Jin, Xueying Sha, Xiaobing Li, Zhe Wang, \\ and Xinwei Li† \\ Key Laboratory of Zoonosis, Ministry of Education, College of Veterinary Medicine, Jilin University, 5333 Xi'an Road, Changchun, \\ 130062, Jilin, China
}

\begin{abstract}
Dairy cows with ketosis are characterized by high blood concentrations of ketone bodies and hepatic lipid metabolism disorder. The discrepancies in the abundance of mRNA encoding a variety of hepatic candidate genes in varying degrees of ketotic cows represent specific responses of the liver to the challenge of fatty acids and ketone bodies. Importantly, the expression disorder of hepatic genes involved in lipid metabolism plays a promoting role in the onset and progression of ketosis. Thus, the aim of this study was to investigate the expression patterns of genes involved in the hepatic fatty acids uptake, transport, activation, $\beta$-oxidation, synthesis, and esterification in the cows with subclinical ketosis (SCK) or clinical ketosis (CK). Twenty-four cows were selected into control $[\mathrm{n}=8$, $\beta$-hydroxybutyrate $(\mathrm{BHB}) \leq 0.6 \mathrm{~m} M]$, SCK $(\mathrm{n}=8,3.0$ $>$ BHB $\geq 1.2 \mathrm{mM})$, and $\mathrm{CK}(\mathrm{n}=8$, BHB $\geq 3.0 \mathrm{mM})$ groups according to the blood $\mathrm{BHB}$ concentration and clinical symptoms. The accumulation of hepatic lipid, as indicated by triglycerides (TG) contents and Oil Red O and hematoxylin and eosin staining, was pronouncedly exacerbated in the tCK group compared with the control and SCK groups. The hepatic mRNA expression of fatty acids transport and activation genes, liver fatty acid-binding protein (FABP1) and long-chain acyl-CoA synthetase 1 (ACSL1), were both significantly higher in the SCK and CK groups than in the control group. The expression levels of peroxisome proliferator-activated receptor $\alpha(P P A R A)$ and its target genes, carnitine palmitoyltransferase $1 \mathrm{~A}(C P T 1 A)$ and carnitine palmitoyltransferase 2 (CPT2), were significantly elevated in the SCK group but reduced in the CK group compared
\end{abstract}

Received April 23, 2018

Accepted September 29, 2018.

*These authors contributed equally to this work.

†Corresponding author: lixinwei100@126.com with control group. Furthermore, the gene expression level of sterol regulatory element-binding protein 1 (SREBP1) and the protein expression level of sterol regulatory element-binding protein $1 \mathrm{c}$ and its target genes acetyl-CoA carboxylase 1 (ACC1), fatty acid synthase $(F A S)$, and stearoyl-CoA desaturase-1 (SCD1) and TG synthesis genes diacylglycerol acyltransferase 1 (DGAT1) and diacylglycerol acyltransferase 2 (DGAT2) were significantly higher in the CK group relative to the control group. In short, the present data indicated that hepatic fatty acids uptake, transport, and activation are significantly increased in cows with SCK and CK, hepatic fatty acids $\beta$-oxidation is significantly increased in SCK cows but markedly decreased in CK cows, and hepatic fatty acids and TG synthesis are significantly increased in CK cows, thereby inducing hepatic steatosis in CK cows.

Key words: ketosis, liver, lipid metabolism, fatty acids

\section{INTRODUCTION}

Ketosis, present at either a subclinical or clinical level, is a common metabolic condition in modern highproducing dairy cows (Vanholder et al., 2015). Highyielding dairy cows suffer from negative energy balance (NEB) and decreased insulin sensitivity during early lactation because of energy expenditure resulting from milk production and limited feed intake (Yuan et al., 2012; Kawashima et al., 2016). Negative energy balance initiates fat mobilization and a subsequent increase in the blood concentrations of fatty acids (Gross et al., 2013); high concentrations of fatty acids can impair the insulin signaling pathway, thereby decreasing the insulin sensitivity (Barazzoni et al., 2012; Gao et al., 2018). The decreased insulin sensitivity can further exacerbate fat mobilization and increase the blood concentrations of fatty acids in early-lactation cows, thereby initiating a vicious cycle (De Koster et al., 2015). Fatty acids are energy-rich molecules and play important roles in the induction of hepatic lipid metabolic disorder of dairy cows during the transition period (Li et al., 2013). Ex- 
cessive fatty acids absorbed by liver from plasma can be metabolized into ketones in hepatocytes, thereby inducing subclinical ketosis (SCK) or clinical ketosis (CK; Ospina et al., 2010; White, 2015). Subclinical ketosis was defined as BHB concentration $<3.0$ and $\geq 1.2 \mathrm{~m} M$ in the absence of clinical sighs, whereas CK was defined as BHB concentration $\geq 3.0 \mathrm{~m} M$ (McArt et al., 2011; Du et al., 2018). The incidence of SCK ranges from 15 to $60 \%$ in dairy cows, whereas CK occurs in 2 to $15 \%$ (McArt et al., 2011). More importantly, ketosis has an economic impact on the herd, involving decreased milk production, increased incidence and duration of common postpartum diseases (metritis, mastitis, milk fever, lameness, gastrointestinal disorders, and displaced abomasum) and fresh cow diseases, increased time to conception, and an increased risk of culling (McLaren et al., 2006; Ospina et al., 2010; Berge and Vertenten, 2014). Therefore, identifying the mechanism of the onset and progression of ketosis is of immediate importance for finding the effective ketosis treatment strategies.

It is clear that the disturbances of fatty acid uptake, transport, activation, oxidation, synthesis, and esterification play promoting roles in the onset and progression of the ketosis (White, 2015). The expression of hepatic lipid metabolic genes involved in the above processes were mainly regulated by 2 transcription factors, peroxisome proliferator-activated receptor $\alpha(\mathbf{P P A R} \boldsymbol{\alpha})$ and sterol regulatory element-binding protein 1c (SREBP1c;Li et al., 2015; Kersten and Stienstra, 2017). The PPAR $\alpha$ is a ligand-activated transcription factor that plays a key role in the regulation of the expression of fatty acids $\beta$-oxidation an uptake and transport genes, including carnitine palmitoyltransferase 1A (CPT1A) and carnitine palmitoyltransferase 2 (CPT2; Qiu et al., 2008). Everett et al. (2000) reported that PPAR $\alpha$ knockout mice showed severe hepatic steatosis and a significantly higher blood concentration of triglycerides (TG). The protein SREBP-1c governs lipogenesis through the transcriptional regulation of lipogenic genes (ACC1, FAS, and SCD1) and TG synthesis genes (DGAT1 and DGAT2; Porstmann et al., 2005). The protein SREBP-1c can sense high levels of fatty acids, and overexpressed SREBP-1c can upregulate the expression of lipid synthesis genes in cow hepatocytes $(\mathrm{Li}$ et al., 2015). Therefore, the expression disorder of above genes may participate in the development of ketosis.

The expression levels of PPAR $\alpha$ and SREBP-1c and their target genes in the liver of SCK and CK cows were not well characterized in previous studies, especially in CK cows. Therefore, the aim of this study was to investigate the expression patterns of hepatic candidate genes involved in fatty acid uptake, transport, activa- tion, $\beta$-oxidation, synthesis, and esterification in cows with SCK or CK. The results can provide insights into the understanding of molecular mechanism of ketosis in dairy cows.

\section{MATERIALS AND METHODS}

All animal protocols were approved by the Ethics Committee for Animal Care and Use of Jilin University [2016 clinical trial (2016-0914); Changchun, China]. The animals received humane care according to the principles and specific guidelines presented in Guidelines for the Care and Use of Agricultural Animals in Research and Teaching (FASS, 2010).

\section{Animals}

Dairy cows were selected from a 7,000-cow dairy farm located in Changchun City, Jilin Province, China. Total mixed rations formulated to meet lactating cow nutritional requirements were fed ad libitum. The basal diet formulation is shown in Table 1. All cows were subjected to routine physical examination to guarantee the cows were free from other co-morbidities. First, we chose lactating Holstein cows with similar numbers of lactation (median $=3$, range $=2$ to 4 ) and DIM (median $=6 \mathrm{~d}$, range $=3$ to $10 \mathrm{~d}$ ). The cows were classified as suspected CK by veterinarians if feed intake, milk yield, or both were reduced and a nitroprusside test for ketone bodies in milk was positive (Du et al., 2018). The cows were classified as suspected healthy or SCK by veterinarians if absence clinical symptoms of ketosis. Subsequently, the blood concentration of BHB in these cows was measured. According to the clinical symptoms and serum BHB concentration (Itle et al., 2015; Du et al., 2018), 8 CK cows with serum BHB concentration higher than $3 \mathrm{mM}, 8$ SCK cows with serum BHB concentration higher than $1.2 \mathrm{~m} M$ and less than 3 $\mathrm{m} M$, and 8 control cows with serum BHB concentration less than $0.6 \mathrm{mM}$ were randomly selected. The basic description of the selected cows is provided in Table 2 .

Blood samples were collected on 3 consecutive days via coccygeal venipuncture between 0700 and $0900 \mathrm{~h}$ before feeding. The blood concentration of $\mathrm{BHB}$ was detected immediately using a Medisense Optium (Abbott Diabetes Care Inc., Alameda, CA; farm assay) with $\beta$-ketone test strips (Abbott Diabetes Care Inc.). The rest of the blood samples were immediately centrifuged at $1,900 \times g$ for $15 \mathrm{~min}$ at $4^{\circ} \mathrm{C}$. The serum was obtained and stored at $-80^{\circ} \mathrm{C}$ until analysis. The blood concentration of BHB was detected once again on the same day using a Hitachi 7170 autoanalyzer (Hitachi, Tokyo, Japan; laboratory assay) with a commercially 
Table 1. Ingredient and nutrient composition of the diets

\begin{tabular}{lc}
\hline Item (\% of DM, unless noted) & Measurement \\
\hline Ingredient & 40.0 \\
Corn silage & 35.0 \\
Corn & 8.0 \\
Wheat bran & 5.0 \\
Soybean meal & 8.0 \\
Sunflower & 1.0 \\
NaCl & 1.8 \\
Premix ${ }^{1}$ & 1.2 \\
NaHCO & \\
Total & 100.0 \\
Nutrient composition & \\
NE & (MJ/kg) \\
CP & 6.7 \\
NDF & 15.2 \\
ADF & 33.5 \\
NFC & 17.2 \\
Ca & 40.4 \\
P & 0.7 \\
\hline
\end{tabular}

${ }^{1}$ The premix provided the following per $\mathrm{kg}$ of diet: vitamin A 200,000 IU, vitamin D 70,000 IU, vitamin E 1,000 IU, Fe 2,000 mg, Cu 600 mg,

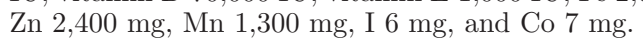

available kit (Randox Laboratories, Crumlin, UK) to ensure the accuracy of the results. The blood glucose and fatty acids concentrations were detected using a Hitachi 7170 autoanalyzer (Hitachi).

After selection, liver samples were taken from the 11 th or 12 th right intercostal space twice by an experienced veterinarian using a liver puncture needle (Shanghai Surgical Equipment Factory, Shanghai, China). Before liver biopsy, the intercostal space was shaved, sanitized with iodine scrub and $75 \%$ alcohol, and anesthetized with a subcutaneous injection of $2 \%$ lidocaine $\mathrm{HCl}$ (Sigma-Aldrich Co., St. Louis, MO). A scalpel blade was used to make a 3 -mm stab incision in the skin. The puncture needle was then inserted through the intercostal muscle and into the liver. The liver tissue biopsies (approximately $200 \mathrm{mg}$ and $3 \mathrm{~cm}$, respectively) were immediately frozen in liquid nitrogen or fixed with $4 \%$ paraformaldehyde or OCT compound (Sakura Finetek Co., Torrance, CA).

\section{Measurement of Liver TG Contents}

The TG contents were measured using an enzymatic kit (E1013, Applygen Technologies Inc., Beijing, China) following the manufacturer's instructions (http://www.applygen.com/product/shenghuaceding/ ganyousanzhi/109.html). Briefly, approximately $50 \mathrm{mg}$ of liver tissue was chopped and homogenized in $1 \mathrm{~mL}$ of lysis buffer. Part of the supernatant was taken to determine the total protein concentrations using the Bicinchoninic acid assay (BCA assay; P1511, Applygen Technologies Inc.). The remaining supernatant was heated in water bath $\left(70^{\circ} \mathrm{C}\right)$ for $10 \mathrm{~min}$, and then was centrifuged at $800 \times g$ for 5 min at room temperature. Ten-microliter aliquots of supernatant were then mixed with $190 \mu \mathrm{L}$ of chromogenic liquid for TG assay. The mixture's absorbance at $550 \mathrm{~nm}$ was proportional to the concentration of TG in each sample. Each sample ( $\mathrm{n}=8$ cows per group) was determined in triplicate. The TG values were expressed as a percentage of wet weight basis.

\section{Histomorphology Analysis}

Tissue samples from the livers of each cow $(\mathrm{n}=8$ cows per group for each staining) were used to evaluate the histomorphology. The histological features were observed and captured at $200 \times$ under a light microscope (Olympus, Tokyo, Japan).

The frozen liver sections that were prepared using OCT compound were subjected to Oil Red O staining to visualize lipid droplets in the liver. Briefly, liver tissues were frozen in OCT compound (Sakura Finetek Co.), sectioned at $8 \mu \mathrm{m}$ at $-18^{\circ} \mathrm{C}$, stained with Oil Red O (Sigma-Aldrich Co.), and counterstained with hematoxylin.

The liver sections that were embedded in paraffin were subjected to hematoxylin and eosin $(\mathbf{H} \& \mathbf{E})$ staining to observe the distribution of accumulated lipid. Briefly, samples were fixed in $4 \%$ paraformaldehyde overnight, dehydrated, cleared, and embedded in paraf-

Table 2. Basic description (median; interquartile range) of the control and subclinical (SCK) and clinical ketosis (CK) cows ${ }^{1}$

\begin{tabular}{|c|c|c|c|}
\hline Item & Control $(\mathrm{n}=8)$ & SCK cows $(\mathrm{n}=8)$ & CK cows $(n=8)$ \\
\hline Milk production ( $\mathrm{kg}$ of milk/cow per day) & $30.3 ; 2.625^{\mathrm{a}}$ & $28.65 ; 2.4^{\mathrm{a}}$ & $25.45 ; 2.95^{\mathrm{b}}$ \\
\hline DIM at the start of blood sampling and milk yield measurement period (day) & $5 ; 2.5^{\mathrm{a}}$ & $7 ; 1.75^{\mathrm{a}}$ & $8 ; 1.75^{\mathrm{a}}$ \\
\hline $\mathrm{BHB}(\mathrm{m} M)$ & $0.39 ; 0.1025^{\mathrm{a}}$ & $1.805 ; 0.3925^{\mathrm{b}}$ & $3.87 ; 0.425^{\mathrm{c}}$ \\
\hline Fatty acids $(\mathrm{m} M)$ & $0.195 ; 0.1225^{\mathrm{a}}$ & $0.365 ; 0.1275^{\mathrm{b}}$ & $1.105 ; 0.29^{\mathrm{b}}$ \\
\hline Glucose $(\mathrm{m} M)$ & $3.93 ; 0.235^{\mathrm{a}}$ & $2.98 ; 0.1925^{\mathrm{b}}$ & $2.285 ; 0.23^{\mathrm{c}}$ \\
\hline
\end{tabular}


fin. Sections of 6 to $8 \mu \mathrm{m}$ in thickness were cut and stained with $\mathrm{H} \& \mathrm{E}$.

\section{RNA Extraction and Quantitative Real-Time PCR Assay}

The total RNA was extracted from liver using RNAiso Plus (9109, TaKaRa Biotechnology Co. Ltd., Dalian, China) according to the manufacturer's instructions (http://www.takarabiomed.com.cn/DownLoad/9108 -9109.pdf). The purity of RNA was measured by calculating the ratio of UV activity at $260 / 280 \mathrm{~nm}$ using K5500 Micro-Spectrophotometer (Beijing Kaiao Technology Development Co. Ltd., Beijing, China). The concentration of purified RNA was determined by UV spectrum at $260 \mathrm{~nm}$. The cDNA was then reverse-transcripted from $5 \mu \mathrm{g}$ of purified total RNA using a reverse transcription kit (RR047A, TaKaRa Biotechnology Co. Ltd.). The relative mRNA expression of target genes were detected using the FastStart Universal SYBR Green Master (ROX) (4913850001, Roche, Norwalk, $\mathrm{CT}$ ) on the 7500 Real-Time PCR System (Applied Biosystems Inc., Waltham, MA). Each sample ( $\mathrm{n}=8$ cows per group) was performed in triplicates. The primers of target genes (list in Table 3) were designed by Primer Express software (Applied Biosystems Inc.) according to the gene sequences published in GeneBank. The reaction conditions were $95^{\circ} \mathrm{C}$ for $3 \mathrm{~min}$, followed by
40 cycles of $95^{\circ} \mathrm{C}$ for $15 \mathrm{~s}$ and $60^{\circ} \mathrm{C}$ for $1 \mathrm{~min}$. The relative quantitation values normalized to the geometric mean of each reference gene's Cq. Quantification cycle values were extrapolated using $2^{-\Delta \Delta \mathrm{Cq}}$ method. ACTB and $G A P D H$ genes were the reference genes stably expressed in different groups (Supplemental Figure S1A and B, https://doi.org/10.3168/jds.2018-14965; Morey et al., 2011).

\section{Protein Extraction and Western Blotting Assay}

Protein abundance of SREBP-1c, PPAR $\alpha$, and $\beta$-actin were determined by semiquantitative Western blotting. Total proteins were extracted from liver tissue and prepared for Western blotting according to the manufacturer's instructions (P0013B, Beyotime Institute of Biotechnology, Jiangsu, China; http://www .beyotime.com/product/P0013B.htm). The BCA assay (P1511, Applygen Technologies Inc.) was performed to determine protein concentrations, which were used to standardize the quantity of total protein loaded onto each gel. Proteins (30 $\mu \mathrm{g} /$ lane) were separated in $15 \%$ SDS-polyacrylamide gels and electrotransferred onto polyvinylidine fluoride membranes. Following transfer, membranes were blocked in 3\% BSA-Tris-buffered saline-Tween 20 at room temperature for $4 \mathrm{~h}$. Blots were incubated with SREBP-1c antibody (1:500; Cat. NB100-2215, Novus Biologicals, Littleton, CO),

Table 3. Primer sequences

\begin{tabular}{|c|c|c|c|c|}
\hline Gene & Sequence number & Primer sequences $\left(5^{\prime}-3^{\prime}\right)$ & $\begin{array}{l}\text { Length } \\
\text { (bp) }\end{array}$ & $\begin{array}{c}\text { Annealing } \\
\text { temperature }\left({ }^{\circ} \mathrm{C}\right)\end{array}$ \\
\hline PPARA & NM_001034036.1 & $\begin{array}{l}\text { Forward (F): TCAGATGGCTCCGTTATT } \\
\text { Reverse (R): CCCGCAGATCCTACACT }\end{array}$ & 132 & 60 \\
\hline$D G A T 1$ & NM_174693.2 & $\begin{array}{l}\text { F: GACACAGACAAGGACGGAGA } \\
\text { R: ACACAGACAAGGACGGAGA } \\
\text { R: CAGCATCACCACACACCAA }\end{array}$ & 141 & 60 \\
\hline CPT1A & NM_001304989.2 & $\begin{array}{l}\text { F: ACGCCGTGAAGTATAACCCT } \\
\text { R: CCAAAAATCGCTTGTCCCTT }\end{array}$ & 119 & 60 \\
\hline CPT2 & NM_001045889.2 & $\begin{array}{l}\text { F: CACCATTAGAAGATACCTCAGTGC } \\
\text { R: TCCAGTTTCAAAACTCTTACACAACT }\end{array}$ & 94 & 60 \\
\hline$A C S L 1$ & NM_001076085.1 & $\begin{array}{l}\text { F: CAAGCCTCCAGTACCTGAAGATC } \\
\text { R: AACGTGTTCTCTGTCATTTTCACAA }\end{array}$ & 138 & 60 \\
\hline$F A S$ & NM_001012669.1 & $\begin{array}{l}\text { F: ACAGCCTCTTCCTGTTTGACG } \\
\text { R: CTCTGCACGATCAGCTCGAC }\end{array}$ & 144 & 60 \\
\hline $\mathrm{ACTB}$ & NM_173979.3 & $\begin{array}{l}\text { F: CCTGCGGCATTCACGAAACTAC } \\
\text { R: ACTCCTGCTTGCTGATCCACATC }\end{array}$ & 273 & 60 \\
\hline$G A P D H$ & NM_001034034.2 & $\begin{array}{l}\text { F: GGGTCATCATCTCTGCACCT } \\
\text { R: ACAGTCTTCTGGGTGGCAGT }\end{array}$ & 211 & 60 \\
\hline
\end{tabular}


PPAR $\alpha$ antibody (1:500; Cat. ab126285, Abcam, Cambridge, UK), or $\beta$-actin antibody (1:1,000; sc-47778; Santa Cruz Biotechnology, Santa Cruz, CA) overnight at $4^{\circ} \mathrm{C}$, followed by incubation with an appropriate secondary antibody at room temperature for $45 \mathrm{~min}$. Immunoreactive bands were visualized by enhanced chemiluminescence solution (Beyotime Biotechnology Inc.) and imaged using a simple protein imager (ProteinSimple, Santa Clara, CA). Each sample ( $\mathrm{n}=8$ cows per group) was run in triplicate. Protein gray intensity was quantified by Image-Pro Plus 6.0 (Media Cybernetics, Bethesda, MD) normalized to $\beta$-actin (Morey et al., 2011).

\section{Statistical Analysis}

Each measurement was repeated at least 3 independent times. All data were analyzed using the appropriate statistical analysis methods with the SPSS 19.0 software (SPSS Inc., Chicago, IL). All data were tested for normality and homoscedasticity using the Shapiro-Wilk and Levene tests, respectively. For data with Gaussian distribution, one-way ANOVA was performed for multiple comparisons with Bonferroni correction for data meeting homogeneity of variance or with Tamhane's $\mathrm{T} 2$ analysis for data of heteroscedasticity. For data sets with skewed distribution, nonparametric statistical analysis was performed using the Kruskal-Wallis test followed by the Dunn test for multiple comparisons.
Data were presented as the mean \pm standard error of the mean or the median and interquartile range; $P<$ 0.05 was considered to be statistically significant and $P$ $<0.01$ was marked significant compared with control group.

\section{RESULTS}

\section{Dairy Cows with Ketosis Displayed Hepatic Lipid Accumulation}

As shown in Table 2, the blood concentrations of BHB and fatty acids were significantly higher in ketotic cows (SCK and CK) than in control cows. Conversely, the blood concentration of glucose was significantly lower in ketotic cows (SCK and CK) than in control cows, especially in the CK cows. Moreover, the hepatic TG contents of CK cows was significantly higher than that of SCK and control cows (Figure 1A, $P<0.01$ ). Oil Red $\mathrm{O}$ and $\mathrm{H} \& \mathrm{E}$ staining further demonstrated that the CK cows displayed significantly hepatic steatosis (Figure 1B).

\section{Parameters Related to Fatty Acid Uptake and Activation in the Liver of Ketotic Cows}

Abundance of mRNA of hepatic FABP1 was higher in the SCK cows (Figure 2A, $P<0.01$ ) and CK cows (Figure $2 \mathrm{~A}, P<0.05)$ relative to control cows. Similar-

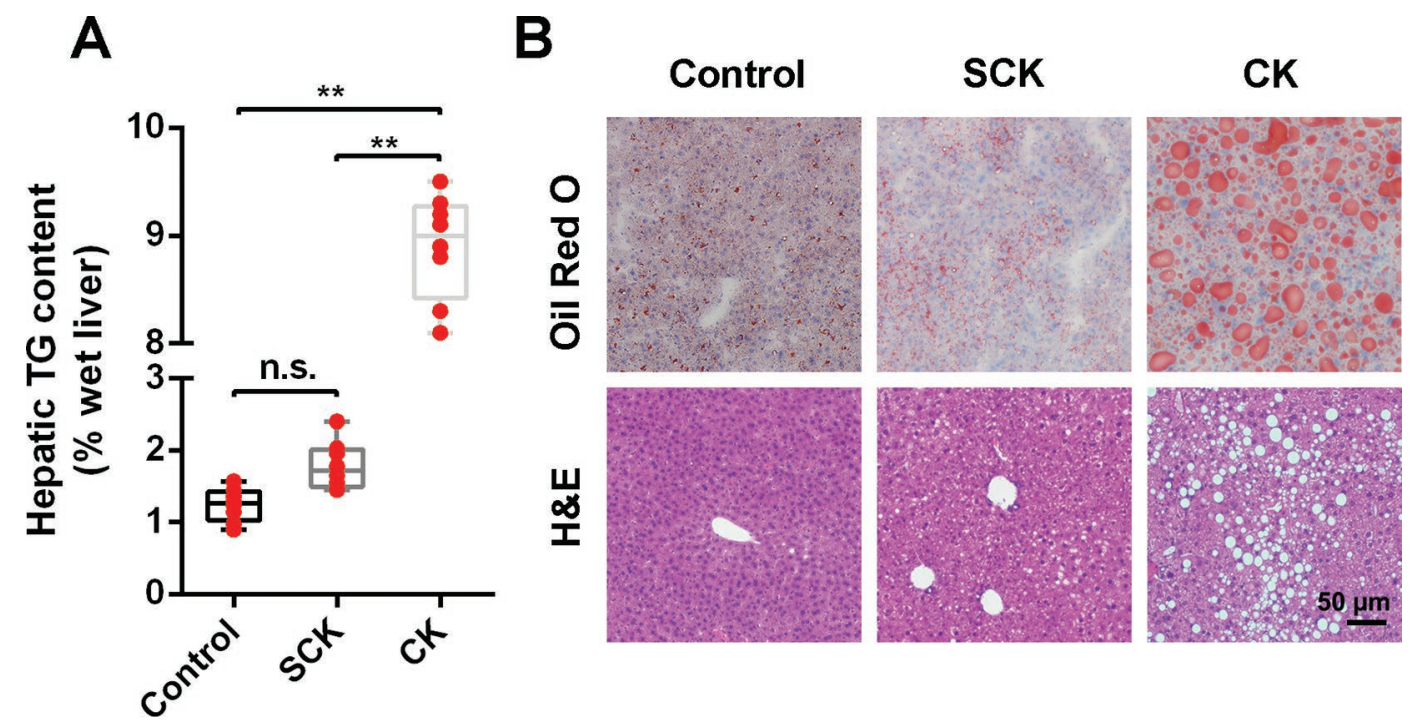

Figure 1. Hepatic triglyceride (TG) contents and histomorphology analysis in control and subclinical (SCK) and clinical ketosis (CK) groups ( $\mathrm{n}=8$ cows per group). (A) Hepatic TG contents in control, SCK, and CK cows; (B) representative images stained with hepatic Oil Red O (top) and hematoxylin and eosin (H\&E; bottom) of control, SCK, and CK cows. Scale bar $=50 \mu \mathrm{m}$. For the box plots, boundaries represent the 25th and 75th percentiles, whiskers show minimum and maximum data, center lines are medians, and every point represents an individual sample. ${ }^{*} P<0.05,{ }^{*} P<0.01$, n.s. = not significant by Kruskal-Wallis test followed by Dunn test. Results are representative of at least 3 independent measurements. 
A

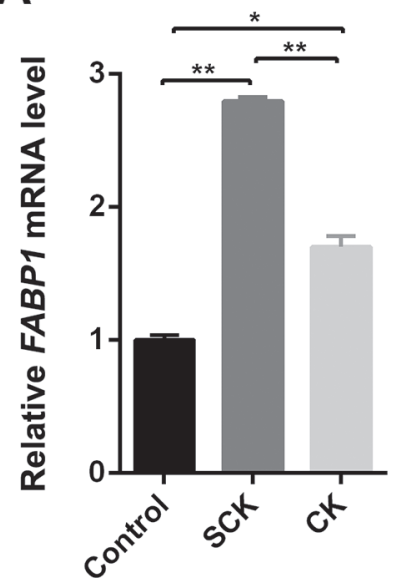

B

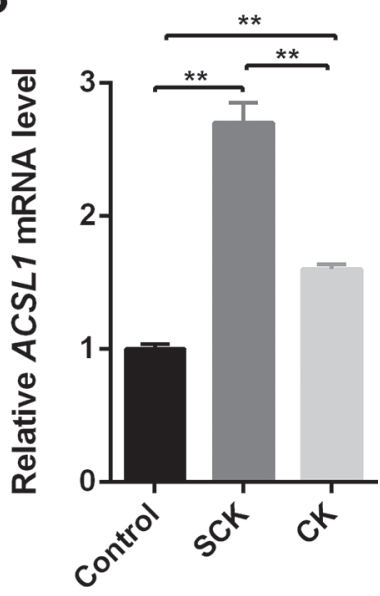

Figure 2. The mRNA expression levels of hepatic FABP1 and ACSL1 in control and subclinical (SCK) and clinical ketosis (CK) groups. Cow grouping was as described in Figure 1. (A) Relative mRNA expression level of FABP1 in control, SCK, and CK cows; (B) relative mRNA expression level of ACSL1 in control, SCK, and CK cows. The data are presented as the mean \pm SEM; $* P<0.05$ and ${ }^{* *} P$ $<0.01$ by one-way ANOVA with subsequent Bonferroni correction. Results are representative of at least 3 independent measurements.

ly, the mRNA abundance of hepatic ACSL1 was higher in the ketotic cows (SCK and $\mathrm{CK}$ ) relative to control cows (Figure 2B, $P<0.01$ ). These results indicate that the intracellular transport and activation of fatty acids were significantly increased in the liver of ketotic cows.

\section{Parameters Related to Fatty Acid $\beta$-Oxidation in the Liver of Ketotic Cows}

As shown in Figure 3, the hepatic mRNA and protein expression of PPAR $\alpha$ were higher in SCK cows than in control cows (Figure $3 \mathrm{~A}$ and $\mathrm{B}, P<0.01$ ). However, the mRNA and protein expression of PPAR $\alpha$ were lower in CK cows than in control cows (Figure 3A and $\mathrm{B}, P<0.05)$. To further investigate the hepatic fatty acid $\beta$-oxidation in ketotic cows, the mRNA expression of PPARA target genes, CPT1A and CPT2, were detected, which transfer long-chain acyl-CoA into the mitochondria for $\beta$-oxidation. The hepatic mRNA levels of above genes showed the similar trends with PPAR $\alpha$ in CK and SCK cows (Figure 3C, D). These results indicate that fatty acid $\beta$-oxidation was significantly increased in SCK cows but markedly decreased in CK cows.

\section{Parameters Related to Lipid Synthesis in the Liver of Ketotic Cows}

To investigate the hepatic lipid synthesis in ketotic cows, the mRNA expression of SREBP1 and the pro-

tein expression of SREBP-1c, the crucial transcription factor of lipid biosynthesis, were detected. As shown in Figure 4, the hepatic mRNA level of SREBP1 and protein level of SREBP-1c were significantly higher in CK cows than in SCK and control cows (Figure 4A and $\mathrm{B}, P<0.01)$. We also found that the hepatic mRNA level of SREBP1 and protein level of SREBP-1c were mildly higher in SCK cows than in control cows, but we observed no statistical significance (Figure 4A and $\mathrm{B}, P>0.05)$. We further detected the mRNA expression of SREBP-1c target genes, ACC1, FAS, and $S C D 1$, which are the key rate-controlling enzymes in lipid synthesis. The mRNA levels of $A C C 1, F A S$, and $S C D 1$ were higher in CK cows than in SCK and control cows (Figure $4 \mathrm{C}$ to E, $P<0.01$ ); however, only $A C C 1$ expression was markedly higher in SCK cows relative to control cows (Figure $4 \mathrm{C}, P<0.05$ ). Furthermore, the mRNA levels of DGAT1 and DGAT2, the mediators of the TG synthesis, were higher in the liver of cows with CK than those of control and SCK cows (Figure $4 \mathrm{~F}$ and G, $P<0.01$ ), and the mRNA level of DGAT1 was higher in SCK cows than in control cows (Figure 4F, $P<0.05)$. Taken together, these results indicate that the hepatic lipid synthesis of CK cows is significantly increased compared with SCK and control cows.

\section{DISCUSSION}

During lactation, various metabolic and endocrine adaptations are necessary to support the increased glucose requirements resulting from milk production (Herdt, 2000; Drackley et al., 2001). Increasing evidence demonstrated that ketotic cows suffered from NEB and decreased insulin sensitivity, both of which could initiate fat mobilization and increase the blood concentrations of fatty acids (Yuan et al., 2012; De Koster et al., 2015; Kawashima et al., 2016). High concentrations of fatty acids could impair the hepatic insulin signaling pathway and further decrease insulin sensitivity, which in turn disturbed the lipid metabolism (Barazzoni et al., 2012; Gao et al., 2018). Furthermore, the changes of many hormones involved in ketotic progression, such as fibroblast growth factor-21 (FGF-21) and bST (Schlegel et al., 2013; Gohary et al., 2014). Xu et al. (2016) reported that the blood concentration of FGF-21 was significantly decreased in the ketotic cows. Du et al. (2018) also reported that uncoupling of the bST axis might be a cause of ketosis. The disordered bST axis promotes lipolysis in adipose tissue and further increases blood fatty acid concentration (Corbit et al., 2017). Overloaded fatty acids not only can be metabolized into ketone bodies (BHB, acetoacetate, and acetone) or esterified to TG, but also can act as signaling molecules regulating the expression of lipid 
metabolism genes (Duplus et al., 2000; Jump et al., 2005). Therefore, the impaired insulin sensitivity and $\mathrm{bST}$ axis and low concentration of FGF-21 might be involved in the development of ketosis and the induction of lipid metabolic disorder. Remarkably, we found that the lipid accumulation of CK cows, as indicated by TG contents and Oil Red $\mathrm{O}$ and $\mathrm{H} \& \mathrm{E}$ staining, was significantly higher than that of control cows, whereas it rose only mildly in SCK cows compared with control cows. These results show that the predominant fatty acids metabolic pathway in cows with varying degrees of ketosis may be different. Meanwhile, we found that the hepatic fatty acid transport and activation genes were markedly upregulated in SCK and CK cows compared with control cows, whereas fatty acid $\beta$-oxidation genes were significantly increased in SCK cows but were markedly decreased in CK cows. Moreover, the fatty acids and TG synthesis genes were significantly augmented in CK cows.

The protein L-FABP regulates the transport of fatty acids in the hepatocytes (Huang et al., 2002). Fatty acids are chemically quite inert and need to be acti- vated to form acyl-CoA in the cell, outside the mitochondrion, before they enter a metabolic pathway (Yan et al., 2015). The ACSL1 protein activates fatty acids to acyl-CoA, thereby enhancing vectorial fatty acid transport across the plasma membrane (Li et al., 2009) and providing substrates for virtually every metabolic pathway that catabolizes fatty acids or synthesizes complex lipids (Jong et al., 2007). In the present study, the hepatic mRNA levels of FABP1 and ACSL1 were significantly increased in the cows with CK or SCK, which promoted the intracellular transport and activation of fatty acids in the liver; this may be because the metabolic adaptations occurred in the liver to further use overloaded fatty acids in ketotic cows. More importantly, enhanced intracellular metabolism of fatty acids (increased activation of fatty acids to acyl-CoA, increased protein-mediated transport of fatty acids, and increased metabolism through both anabolic and catabolic pathways) increases fatty acid uptake (Mashek and Coleman, 2006), which coincides with the study of White (2015), who showed that fatty acid uptake from plasma by the liver is increased in ketotic cows. Li et
A

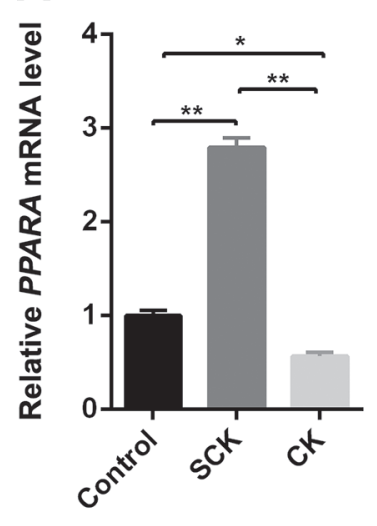

C

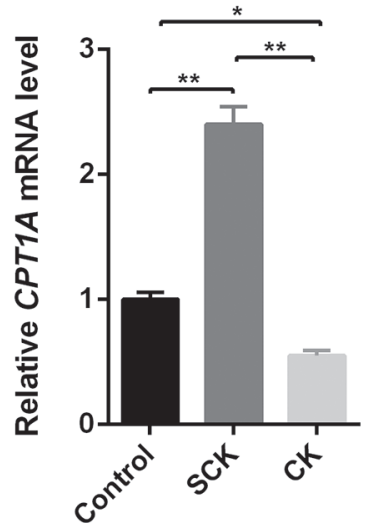

B

$\beta$-actin
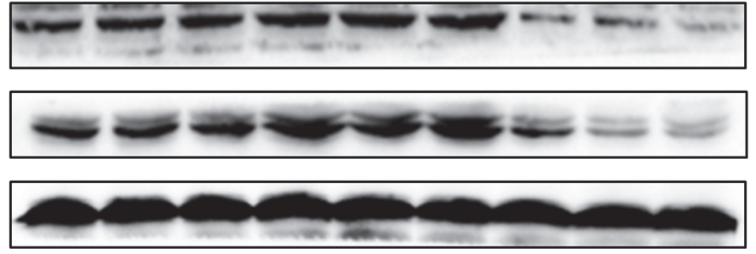

42 kDa
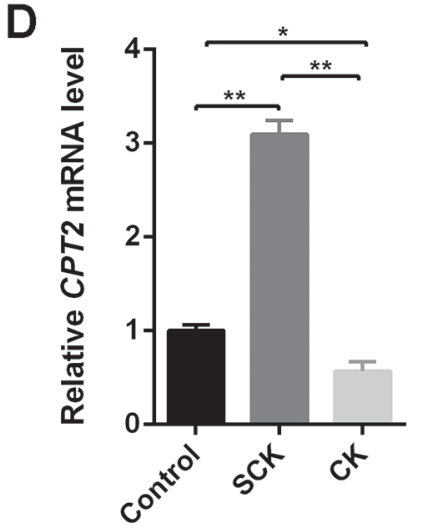

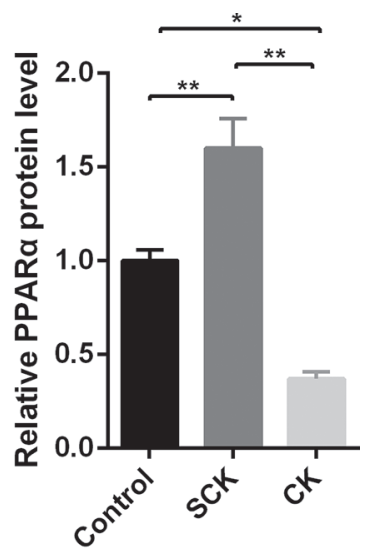

Figure 3. Expression of hepatic PPARA and its target genes in control and subclinical (SCK) and clinical ketosis (CK) groups. Cow grouping was as described in Figure 1. (A) Relative mRNA expression level of hepatic PPARA in control, SCK, and CK cows; (B) representative Western blots (left) and quantification (right) of hepatic PPARA in control, SCK, and CK cows; (C) relative mRNA expression level of CPT1A in control, SCK, and CK cows; and (D) relative mRNA expression level of CPT2 in control, SCK, and CK cows. For all bar plots shown, data are expressed as the mean $\pm \mathrm{SEM} ;{ }^{*} P<0.05$ and ${ }^{* *} P<0.01$ by one-way ANOVA with subsequent Bonferroni correction (A, B, D) or Tamhane's $\mathrm{T} 2$ analysis (C). Results are representative of at least 3 independent measurements. 
al., (2012a) also reported that the expression level of ACSL1 was significantly increased in SCK cows, which further supported our study.

Once activated to acyl-CoA, fatty acids have diverse cellular fates, and the 2 predominant routes of metabolism are degradation via $\beta$-oxidation and incorporation into complex lipids (Mashek and Coleman, 2006). The PPAR $\alpha$ mediates the remodeling of hepatic lipid metabolism via the induction of several rate-limiting enzymes of fatty acid $\beta$-oxidation, such as CPT1A and CPT2 (Li et al., 2013), which can transfer long-chain acyl-CoA into the mitochondria for $\beta$-oxidation (Hou et al., 2008). Our data showed that the expression levels of PPAR $\alpha$ and its target genes, CPT1A and CPT2, in SCK cows were significantly higher than those of control cows, whereas these genes in CK cows were markedly lower than those of control cows. These results indicate that hepatic $\beta$-oxidation of fatty acids was significantly induced in SCK cows but markedly inhibited in CK cows. The reason for the differences between SCK and
CK cows may be due to the limited ability of hepatocytes to oxidize overloaded fatty acids. The expression of hepatic candidate gene-mediated $\beta$-oxidation was proportional to the fatty acid concentrations within the compensation range (Graber et al., 2010). In our SCK cows, hepatocytes were exposed to a relatively low concentration of fatty acids. Hepatocytes could completely or incompletely oxidize fatty acids to improve NEB via upregulating the expression of hepatic fatty acids $\beta$-oxidation genes, such as PPARA, CPT1A, and CPT2. Furthermore, Dann et al. (2005), Loor (2010), and Schlegel et al. (2012) have also shown that PPARA and its target gene CPT1A in the liver are strongly induced at 1 wk postpartum when the blood fatty acids concentration is within the compensation range, which further highlighted the increased hepatic fatty acid $\beta$-oxidation in SCK cows. However, high levels of fatty acids exhibited lipotoxicity and could impair mitochondrial function and further inhibit the $\beta$-oxidation of fatty acids (Finucane et al., 2013; Shi et al., 2015; Song
A
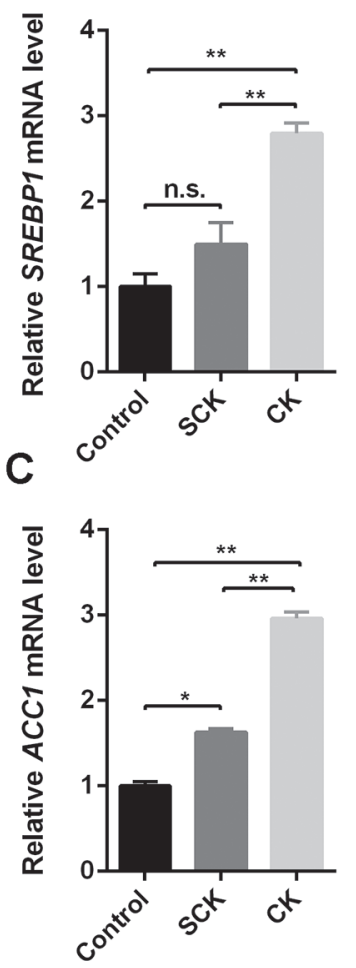

B

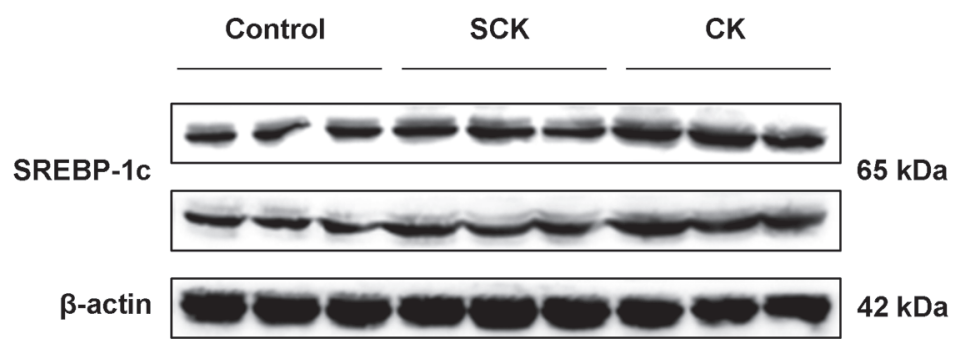

D

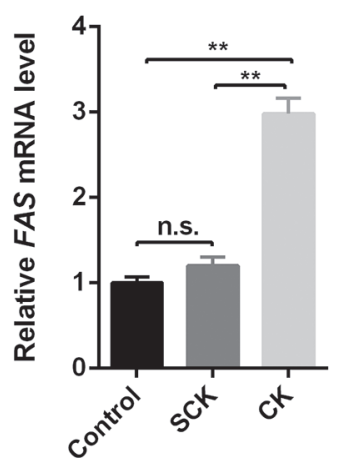

E

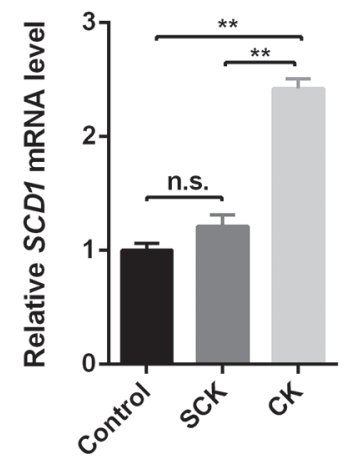

$\mathbf{F}$

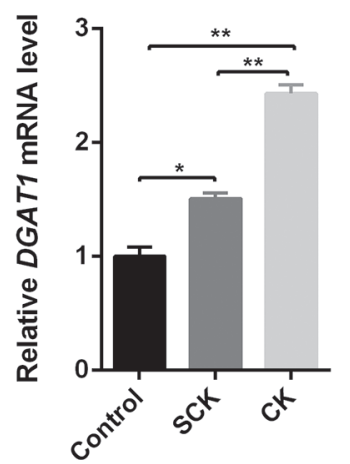

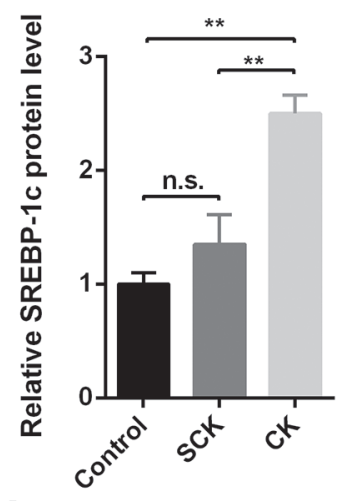

G

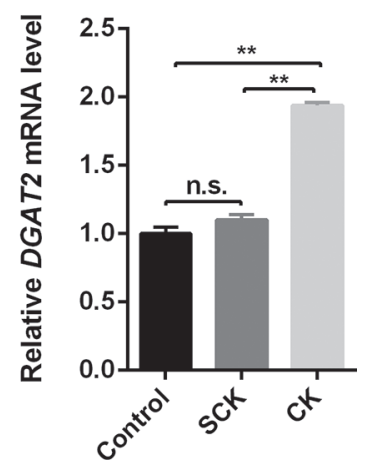

Figure 4. Expression of hepatic SREBP1 and its target genes in control and subclinical (SCK) and clinical ketosis (CK) groups. Cow grouping was as described in Figure 1. (A) Relative mRNA expression level of hepatic SREBP1 in control, SCK, and CK cows; (B) representative Western blots (left) and quantification (right) of hepatic SREBP-1c in control, SCK, and CK cows; (C) relative mRNA expression level of $A C C 1$ in control, SCK, and CK cows; (D) relative mRNA expression level of $F A S$ in control, SCK, and CK cows; (E) relative mRNA expression level of SCD1 in control, SCK, and CK cows; (F) relative mRNA expression level of DGAT1 in control, SCK, and CK cows; and (G) relative mRNA expression level of $D G A T 2$ in control, SCK, and CK cows. For all bar plots shown, data are expressed as the mean \pm SEM; $* P<0.05$, $* * P$ $<0.01$, n.s. $=$ not significant by one-way ANOVA with subsequent Bonferroni correction. Results are representative of at least 3 independent measurements. 
et al., 2016). Data obtained in mice demonstrated that high concentration of long-chain acyl-CoA inhibited the activity of CPT1A and CPT2 (Ciapaite et al., 2011; Flamment et al., 2012). Similarly, CPT1A activity in dairy cows with severe hepatic lipidosis was lower than that in dairy cows without hepatic lipidosis (Mizutani et al., 1999). Accordingly, the decreased expression of PPARA, CPT1A, and CPT2 in CK cows might be due to the inhibition effect of high concentration of fatty acids and long-chain acyl-CoA. However, the threshold of fatty acid concentration that causes these 2 completely opposite effects remains to be further studied.

Changes in hepatic lipid content are the offsetting results of fatty acids utilization and lipid synthesis (Gross et al., 2013). The SREBP-1c is a master transcriptional regulator of lipid synthesis by stimulating the expression of lipogenic genes $A C C 1, F A S, S C D 1, D G A T 1$, and DGAT2 (Li et al., 2014, 2015). Increased expression of hepatic SREBP-1c is relevant in lipid accumulation in the liver of dairy cows (Prodanović et al., 2016), we therefore detected the expression levels of SREBP-1c and its target genes (ACC1, FAS, SCD1, DGAT1, and $D G A T 2)$. The results showed that the protein expression of SREBP-1c and gene expression of TG synthesis genes, SREBP1, DGAT1, and DGAT2, in the liver of CK cows were markedly higher than those of control cows, which was consistent with increased TG accumulation in CK cows. These results indicate that the hepatic TG synthesis of cows with CK was significantly increased. These data were further supported by our previous study (Li et al., 2014, 2015), which showed that the expression of SREBP-1c was significantly increased in cows with hepatic TG accumulation. Meanwhile, the gene expression of SREBP-1c target genes, ACC1, FAS, and $S C D 1$, also known as fatty acid synthesis genes, were significantly higher in the liver of CK cows than those of control cows. These results were in agreement with our previous study, which showed that SREBP-1c could sense high levels of fatty acids and significantly upregulated the expression of $A C C 1, F A S$, and SCD1 in fatty acid-treated $(>0.6 \mathrm{mM})$ cow hepatocytes (Li et al., 2015). More importantly, overexpression of SREBP1c markedly upregulated the expression of $A C C 1, F A S$, and SCD1 (Diraison et al., 2004; Li et al., 2015). Thus, the increased mRNA expression of $A C C 1, F A S$, and $S C D 1$ in CK cows may be a consequence response to the enhanced expression of SREBP-1c. Undoubtedly, most of the fatty acids for TG synthesis come from blood in ketotic cows. The increased expression of fatty acid synthesis genes observed in our CK cows may make a slight contribution to TG synthesis. The contribution of de novo-synthesized fatty acids on TG synthesis remains to be studied in CK cows. Correspondingly, decreased fatty acid $\beta$-oxidation further accelerated he- patic lipid accumulation in CK cows. Taken together, the hepatic lipid accumulation observed in CK cows can be ascribed to the collaborative effect of the decreased fatty acid $\beta$-oxidation and increased lipid synthesis. In addition, $S R E B P 1$ includes 2 isoforms, SREBP1A and $S R E B P 1 C$; $S R E B P 1 A$ is a regulator of cholesterol synthesis beyond activating the fatty acid synthesis (Amemiya-Kudo et al., 2002). A previous study showed that the liver cholesterol content was increased in ketosis (Brumby et al., 1975), which indicates that the expression of SREBP1A may increase in CK cows. This result was in agreement with the increased expression of SREBP1 in our CK cows.

The uptake of fatty acids from plasma by the liver was increased in SCK cows, which means the hepatocyte of SCK cows was exposed to high concentrations of fatty acids compared with control cows. However, we found no statistical significances in the hepatic expression levels of $S R E B P 1 C, F A S, S C D 1$, and DGAT2 between SCK cows and control cows. Remarkably, the expression of fatty acid $\beta$-oxidation genes was significantly increased in SCK cows relative to control cows. Thus, the low rate of lipid synthesis in SCK cows may be due to the increased fatty acid $\beta$-oxidation, which is sufficient to handle the overloaded fatty acids absorbed from blood without the necessity to comprehensively promote lipid synthesis to protect against fatty acidinduced lipotoxicity. Interestingly, hepatic $A C C 1$ and DGAT1 mRNA levels were increased in SCK cows. These results indicate that $A C C 1$ and DGAT1 can be upregulated in a SREBP-1c-independent manner, but the exact mechanism remains to be further studied. These findings in the present study extend the mechanism of hepatic lipid metabolism disorder in ketotic cows.

Gluconeogenesis, which occurs primarily in liver, is essential to meet the glucose requirements in dairy cows (Greenfield et al., 2000). Our results showed that CK cows had significantly lower blood glucose concentration and milk yield compared with SCK and control cows, whereas SCK cows had significantly lower blood glucose concentration compared with control cows. Gluconeogenic substrate is insufficient in ketotic cows compared with healthy cows (Sun et al., 2014). Furthermore, a previous study suggested that a high concentration of fatty acids significantly inhibited the activity of phosphoenolpyruvate carboxykinase and pyruvate carboxylase in hepatocytes, the key enzymes of gluconeogenesis, and further impaired the gluconeogenesis ( $\mathrm{Li}$ et al., 2012b). Thus, although the milk yield was lower in cows with CK relative to control cows, the limited gluconeogenic ability of the liver could not satisfy the demand for glucose, thereby leading the low blood glucose concentration in ketotic cows. However, 
we did not detect the rate of gluconeogenesis in cows with SCK or CK, which was a limitation in our study.

\section{CONCLUSIONS}

The expression of hepatic genes mediated the transport and activation of fatty acids (FABP1 and ACSL1) was significantly increased in SCK and CK cows. The expression of hepatic PPAR $\alpha$ and its target genes mediating the fatty acid $\beta$-oxidation was markedly augmented in SCK cows, but significantly decreased in CK cows. Moreover, hepatic SREBP-1c-mediated fatty acids and TG synthesis genes were significantly increased in CK cows, thereby inducing the hepatic steatosis in CK cows.

\section{ACKNOWLEDGMENTS}

This work was supported by the National Key Research and Development Program (Beijing, China; grant no. 2016YFD0501206), the National Natural Science Foundation of China (Beijing, China; grant nos. 31572581, 31672621, and 31772810), and the Natural Science Foundation of Jilin Province (Changchun, China; grant no. 20170101148JC).

\section{REFERENCES}

Amemiya-Kudo, M., H. Shimano, A. H. Hasty, N. Yahagi, T. Yoshikawa, T. Matsuzaka, H. Okazaki, Y. Tamura, Y. Iizuka, and K. Ohashi. 2002. Transcriptional activities of nuclear SREBP-1a, $-1 \mathrm{c}$, and -2 to different target promoters of lipogenic and cholesterogenic genes. J. Lipid Res. 43:1220-1235.

Barazzoni, R., M. Zanetti, G. G. Cappellari, A. Semolic, M. Boschelle, E. Codarin, A. Pirulli, L. Cattin, and G. Guarnieri. 2012. Fatty acids acutely enhance insulin-induced oxidative stress and cause insulin resistance by increasing mitochondrial reactive oxygen spe-

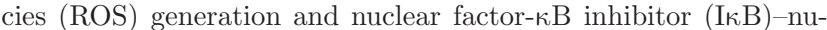
clear factor- $\mathrm{B}(\mathrm{NF \kappa B})$ activation in rat muscle, in the absence of mitochondrial dysfunction. Diabetologia 55:773-782.

Berge, A. C., and G. Vertenten. 2014. A field study to determine the prevalence, dairy herd management systems, and fresh cow clinical conditions associated with ketosis in western European dairy herds. J. Dairy Sci. 97:2145-2154.

Brumby, P. E., M. Anderson, B. Tuckley, J. E. Storry, and K. G. Hibbit. 1975. Lipid metabolism in the cow during starvation-induced ketosis. Biochem. J. 146:609.

Ciapaite, J., N. M. van den Broek, H. T. Brinke, K. Nicolay, J. A. Jeneson, S. M. Houten, and J. J. Prompers. 2011. Differential effects of short- and long-term high-fat diet feeding on hepatic fatty acid metabolism in rats. Biochim. Biophys. Acta 1811:441-451.

Corbit, K. C., J. P. Camporez, J. L. Tran, C. G. Wilson, D. A. Lowe, S. M. Nordstrom, K. Ganeshan, R. J. Perry, G. I. Shulman, and M. J. Jurczak. 2017. Adipocyte JAK2 mediates growth hormoneinduced hepatic insulin resistance. JCI Insight 2:e91001.

Dann, H. M., D. E. Morin, G. A. Bollero, M. R. Murphy, and J. K. Drackley. 2005. Prepartum intake, postpartum induction of ketosis, and periparturient disorders affect the metabolic status of dairy cows. J. Dairy Sci. 88:3249-3264.

De Koster, J. D., M. Hostens, M. V. Eetvelde, K. Hermans, S. Moerman, H. Bogaert, E. Depreester, W. V. D. Broeck, and G. Opsomer. 2015. Insulin response of the glucose and fatty acid metabo- lism in dry dairy cows across a range of body condition scores. J. Dairy Sci. 98:4580-4592.

Diraison, F., L. Parton, P. Ferré, F. Foufelle, C. P. Briscoe, I. Leclerc, and G. A. Rutter. 2004. Over-expression of sterol-regulatory-element-binding protein-1c (SREBP1c) in rat pancreatic islets induces lipogenesis and decreases glucose-stimulated insulin release: modulation by 5 -aminoimidazole-4-carboxamide ribonucleoside (AICAR). Biochem. J. 378:769-778.

Drackley, J. K., T. R. Overton, and G. N. Douglas. 2001. Adaptation of glucose and long-chain fatty acid metabolism in liver of dairy cows during the periparturient period. J. Dairy Sci. 84:E100-E112.

Du, X., Y. Zhu, Z. Peng, Y. Cui, Q. Zhang, Z. Shi, Y. Guan, X. Sha, T. Shen, and Y. Yang. 2018. High concentrations of fatty acids and $\beta$-hydroxybutyrate impair the growth hormone-mediated hepatic JAK2-STAT5 pathway in clinically ketotic cows. J. Dairy Sci. 101:3476-3487.

Duplus, E., M. Glorian, and C. Forest. 2000. Fatty acid regulation of gene transcription. J. Biol. Chem. 275:30749-30752.

Everett, L., A. Galli, and D. Crabb. 2000. The role of hepatic peroxisome proliferator-activated receptors (PPARs) in health and disease. Liver 20:191-199.

FASS. 2010. Guidelines for the Care and Use of Agricultural Animals in Research and Teaching. 3rd ed. FASS Inc., Champaign, IL.

Finucane, F. M., S. J. Sharp, M. Hatunic, A. Sleigh, E. D. L. Rolfe, A. A. Sayer, C. Cooper, S. J. Griffin, D. B. Savage, and N. J. Wareham. 2013. Intrahepatic lipid content and insulin resistance are more strongly associated with impaired NEFA suppression after oral glucose loading than with fasting NEFA levels in healthy older individuals. Int. J. Endocrinol. 2013:870487.

Flamment, M., J. Rieusset, H. Vidal, G. Simard, Y. Malthiery, B. Fromenty, and P.-H. Ducluzeau. 2012. Regulation of hepatic mitochondrial metabolism in response to a high fat diet: A longitudinal study in rats. J. Physiol. Biochem. 68:335-344.

Gao, W., X. Du, L. Lei, H. Wang, M. Zhang, Z. Wang, X. Li, G. Liu, and X. Li. 2018. NEFA-induced ROS impaired insulin signalling through the JNK and p38MAPK pathways in non-alcoholic steatohepatitis. J. Cell. Mol. Med. 22:3408.

Gohary, K., S. J. LeBlanc, K. D. Lissemore, M. W. Overton, M. Von Massow, and T. F. Duffield. 2014. Effect of prepartum administration of recombinant bovine somatotropin on health and performance of lactating dairy cows. J. Dairy Sci. 97:6231-6241.

Graber, M., S. Kohler, T. Kaufmann, M. G. Doherr, R. M. Bruckmaier, and H. A. V. Dorland. 2010. A field study on characteristics and diversity of gene expression in the liver of dairy cows during the transition period. J. Dairy Sci. 93:5200.

Greenfield, R. B., M. J. Cecava, and S. S. Donkin. 2000. Changes in mRNA expression for gluconeogenic enzymes in liver of dairy cattle during the transition to lactation. J. Dairy Sci. 83:1228-1236.

Gross, J. J., F. J. Schwarz, K. Eder, H. A. V. Dorland, and R. M. Bruckmaier. 2013. Liver fat content and lipid metabolism in dairy cows during early lactation and during a mid-lactation feed restriction. J. Dairy Sci. 96:5008-5017.

Herdt, T. H. 2000. Ruminant adaptation to negative energy balance. Influences on the etiology of ketosis and fatty liver. Vet. Clin. North Am. Food Anim. Pract. 16:215-230.

Hou, X., S. Xu, K. A. Maitlandtoolan, K. Sato, B. Jiang, Y. Ido, F Lan, K. Walsh, M. Wierzbicki, and T. J. Verbeuren. 2008. SIRT1 regulates hepatocyte lipid metabolism through activating AMPactivated protein kinase. J. Biol. Chem. 283:20015-20026.

Huang, H., O. Starodub, A. Mcintosh, A. B. Kier, and F. Schroeder. 2002. Liver fatty acid-binding protein targets fatty acids to the nucleus. Real time confocal and multiphoton fluorescence imaging in living cells. J. Biol. Chem. 277:29139-29151.

Itle, A. J., J. M. Huzzey, D. M. Weary, and M. A. von Keyserlingk. 2015. Clinical ketosis and standing behavior in transition cows. J. Dairy Sci. 98:128-134.

Jong, H. D., A. C. Neal, R. A. Coleman, and T. M. Lewin. 2007. Ontogeny of mRNA expression and activity of long-chain acyl-CoA synthetase (ACSL) isoforms in Mus musculus heart. Biochim. Biophys. Acta 1771:75. 
Jump, D. B., D. Botolin, Y. Wang, J. H. Xu, B. Christian, and O. Demeure. 2005. Fatty acid regulation of hepatic gene transcription. J. Nutr. 135:2503-2506.

Kawashima, C., M. Munakata, T. Shimizu, A. Miyamoto, K. Kida, and M. Matsui. 2016. Relationship between the degree of insulin resistance during late gestation and postpartum performance in dairy cows and factors that affect growth and metabolic status of their calves. J. Vet. Med. Sci. 78:739-745.

Kersten, S., and R. Stienstra. 2017. The role and regulation of the peroxisome proliferator activated receptor alpha in human liver. Biochimie 136:75-84.

Li, L. O., J. M. Ellis, H. A. Paich, S. Wang, N. Gong, G. Altshuller, R. J. Thresher, T. R. Koves, S. M. Watkins, and D. M. Muoio. 2009 Liver-specific loss of long chain acyl-CoA synthetase-1 decreases triacylglycerol synthesis and beta-oxidation and alters phospholipid fatty acid composition. J. Biol. Chem. 284:27816-27826.

Li, P., X. B. Li, S. X. Fu, C. C. Wu, X. X. Wang, G. J. Yu, M. Long, Z. Wang, and G. W. Liu. 2012a. Alterations of fatty acid $\beta$-oxidation capability in the liver of ketotic cows. J. Dairy Sci. 95:1759-1766.

Li, X., W. Huang, J. Gu, X. Du, L. Lei, X. Yuan, G. Sun, Z. Wang, X. Li, and G. Liu. 2015. SREBP-1c overactivates ROS-mediated hepatic NF- $\kappa \mathrm{B}$ inflammatory pathway in dairy cows with fatty liver. Cell. Signal. 27:2099-2109.

Li, X., X. Li, B. Ge, C. Hui, Q. Deng, Z. Liu, Z. Liang, G. Liu, and W. Zhe. 2012b. Effects of non-esterified fatty acids on the gluconeogenesis in bovine hepatocytes. Mol. Cell. Biochem. 359:385-388.

Li, X., Y. Li, W. Yang, C. Xiao, S. Fu, Q. Deng, H. Ding, Z. Wang, G. Liu, and X. Li. 2014. SREBP-1c overexpression induces triglycerides accumulation through increasing lipid synthesis and decreasing lipid oxidation and VLDL assembly in bovine hepatocytes. J. Steroid Biochem. Mol. Biol. 143:174-182.

Li, X., H. Chen, Y. Guan, X. B. Li, L. C. Lei, J. X. Liu, L. H. Yin, G. W. Liu, and Z. Wang. 2013. Acetic acid activates the AMPactivated protein kinase signaling pathway to regulate lipid metabolism in bovine hepatocytes. PLoS One 8:e67880.

Loor, J. J. 2010. Genomics of metabolic adaptations in the peripartal cow. Animal 4:1110-1139.

Mashek, D. G., and R. A. Coleman. 2006. Cellular fatty acid uptake: the contribution of metabolism. Curr. Opin. Lipidol. 17:274-278.

McArt, J. A. A., D. V. Nydam, P. A. Ospina, and G. R. Oetzel. 2011 A field trial on the effect of propylene glycol on milk yield and resolution of ketosis in fresh cows diagnosed with subclinical ketosis. J. Dairy Sci. 94:6011-6020.

McLaren, C. J., K. D. Lissemore, T. F. Duffield, K. E. Leslie, D. F. Kelton, and B. Grexton. 2006. The relationship between herd level disease incidence and a return over feed index in Ontario dairy herds. Can. Vet. J. 47:767-773.

Mizutani, H., T. Sako, Y. Toyoda, T. Kawabata, N. Urumuhang, H. Koyama, and S. Motoyoshi. 1999. Preliminary studies on hepatic carnitine palmitoyltransferase in dairy cattle with or without fatty liver. Vet. Res. Commun. 23:475.

Morey, S. D., L. K. Mamedova, D. E. Anderson, C. K. Armendariz, E. C. Titgemeyer, and B. J. Bradford. 2011. Effects of encapsulated niacin on metabolism and production of periparturient dairy cows. J. Dairy Sci. 94:5090-5104

Ospina, P. A.. D. V. Nydam, T. Stokol, and T. R. Overton. 2010 Associations of elevated nonesterified fatty acids and beta-hydroxybutyrate concentrations with early lactation reproductive performance and milk production in transition dairy cattle in the northeastern United States. J. Dairy Sci. 93:1596-1603.

Porstmann, T., B. Griffiths, Y. L. Chung, O. Delpuech, J. R. Griffiths, J. Downward, and A. Schulze. 2005. PKB/Akt induces transcription of enzymes involved in cholesterol and fatty acid biosynthesis via activation of SREBP. Oncogene 24:6465-6481.

Prodanović, R., G. Korićanac, I. Vujanac, A. Djordjević, M. Pantelić S. Romić, Z. Stanimirović, and D. Kirovski. 2016. Obesity-driven prepartal hepatic lipid accumulation in dairy cows is associated with increased CD36 and SREBP-1 expression. Res. Vet. Sci 107:16-19.

Qiu, L., X. Wu, J. F. Chau, I. Y. Szeto, W. Y. Tam, Z. Guo, S. K. Chung, P. J. Oates, S. S. Chung, and J. Y. Yang. 2008. Aldose reductase regulates hepatic peroxisome proliferator-activated receptor alpha phosphorylation and activity to impact lipid homeostasis. J. Biol. Chem. 283:17175-17183.

Schlegel, G., J. Keller, F. Hirche, S. Geissler, F. J. Schwarz, R. Ringseis, G. I. Stangl, and K. Eder. 2012. Expression of genes involved in hepatic carnitine synthesis and uptake in dairy cows in the transition period and at different stages of lactation. BMC Vet. Res. 8:28.

Schlegel, G., R. Ringseis, J. Keller, F. J. Schwarz, W. Windisch, and K. Eder. 2013. Expression of fibroblast growth factor 21 in the liver of dairy cows in the transition period and during lactation. J. Anim. Physiol. Anim. Nutr. (Berl.) 97:820-829.

Shi, X., D. Li, Q. Deng, Y. Li, G. Sun, X. Yuan, Y. Song, Z. Wang, X. $\mathrm{Li}$, and X. Li. 2015. NEFAs activate the oxidative stress-mediated $\mathrm{NF}-\kappa \mathrm{B}$ signaling pathway to induce inflammatory response in calf hepatocytes. J. Steroid Biochem. Mol. Biol. 145:103-112.

Song, Y., N. Li, J. Gu, S. Fu, Z. Peng, C. Zhao, Y. Zhang, X. Li, Z. Wang, and X. Li. 2016. $\beta$-Hydroxybutyrate induces bovine hepatocyte apoptosis via an ROS-p38 signaling pathway. J. Dairy Sci. 99:9184.

Sun, L. W., H. Y. Zhang, L. Wu, S. Shu, C. Xia, C. Xu, and J. S. Zheng. 2014. (1)H-Nuclear magnetic resonance-based plasma metabolic profiling of dairy cows with clinical and subclinical ketosis. J. Dairy Sci. 97:1552-1562.

Vanholder, T., J. Papen, R. Bemers, G. Vertenten, and A. C. Berge. 2015. Risk factors for subclinical and clinical ketosis and association with production parameters in dairy cows in the Netherlands. J. Dairy Sci. 98:880-888.

White, H. M. 2015. The role of TCA cycle anaplerosis in ketosis and fatty liver in periparturient dairy cows. Animals (Basel) 5:793-802.

Xu, C., S. Shi, X. Cheng, W. Bo, H. Y. Zhang, and J. Bao. 2014 Investigation on the relationship of insulin resistance and ketosis in dairy cows. J. Vet. Sci. Technol. 5:162. https://doi.org/10.4172/ 2157-7579.1000162.

Xu, C., Q. Xu, Y. Chen, W. Yang, C. Xia, H. Yu, K. Zhu, T. Shen, and Z. Zhang. 2016. FGF-21: Promising biomarker for detecting ketosis in dairy cows. Vet. Res. Commun. 40:49-54.

Yan, S., X. F. Yang, H. L. Liu, N. Fu, Y. Ouyang, and Q. Kai. 2015. Long-chain acyl-CoA synthetase in fatty acid metabolism involved in liver and other diseases: An update. World J. Gastroenterol. $21: 3492-3498$

Yuan, K., R. D. Shaver, S. J. Bertics, M. Espineira, and R. R. Grummer. 2012. Effect of rumen-protected niacin on lipid metabolism, oxidative stress, and performance of transition dairy cows. J. Dairy Sci. 95:2673-2679. 